\title{
Application of bio-economic simulation models for addressing sustainable land management issues for northern Australia.
}

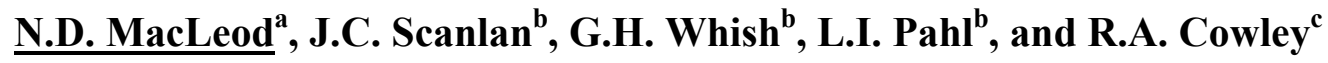 \\ ${ }^{a}$ CSIRO Ecosystem Sciences, Brisbane, Queensland \\ ${ }^{b}$ Department. of Employment, Economic Development and Innovation, Toowoomba, Queensland \\ ${ }^{c}$ Department of Resources, Darwin, Northern Territory \\ Email:neil.macleod@.csiro.au
}

\begin{abstract}
Commencing in 2009, Meat and Livestock Australia has funded the Northern Grazing Systems Project (NGS) which seeks to identify and extend sustainable herd and land management strategies for nine major bio-regions of northern Australia. Conduct of the NGS is built around a multistep framework of scientific reviews, regional industry workshops, bio-economic modelling of the impact of the most promising 'best-bet' options on landscape degradation and production, and regional testing and extension of those options.
\end{abstract}

Bio-economic modelling is a central component of NGS and has been applied to exploring the production, resource condition and financial implications of northern beef enterprises adopting the more promising strategies that are revealed through the science review and workshop phases. The modelling process combines a pasture and animal production model (GRASP) and a dynamic beef herd economic model (ENTERPRISE) to mimic the performance of representative beef enterprises defined at each regional workshop.

NGS is exploring four major herd and management strategies across the regions, including:

(a) Stocking rates,

(b) Wet season pasture spelling,

(c) Prescribed fire, and

(d) Infrastructure.

The paper briefly describes the overall NGS framework and illustrates the application of the modelling process for one of the herd and management strategies, namely stocking rates, in one of the nine bioregions, the Fitzroy River Basin.

The effect of employing variable versus fixed stocking rate strategies on a range of physical (carrying capacity, pasture condition, animal growth) and financial (total enterprise profit) measures is explored for a hypothetical 10,500 ha property located at Duaringa. The stocking rate strategies include set stocking rates and two variable stocking rates that involve either constrained or unlimited variation in response to pasture availability.

The economic results favoured a set stocking strategy over either of the two variable stocking rate strategies. While the unlimited variation strategy did yield the highest profit in any one year of the simulation period, it also yielded the lowest profit in any year and for $50 \%$ of years this measure was negative. Nevertheless, the result is contingent on the actual climate sequence of the simulation period and did differ substantially to that observed in several of the other regions which experienced quite different seasonal sequence.

Keywords: grazing lands, bio-economic modelling, stocking rate, northern Australia 


\section{INTRODUCTION}

Landscape resource degradation is a long-recognised issue for the northern Australian grazing industries (e.g. Tothill and Gillies1993) and much research has been invested in identifying sustainable grazing land management practices, although by and large this has not been well integrated or promoted. Since 2009 Meat and Livestock Australia has funded a significant study, Northern Grazing Systems (NGS), to identify and extend potentially sustainable herd and land management strategies for nine major bioregions across northern Australia. NGS involves a multi-step process: (1) commissioned scientific reviews of past research, (2) landholder participation through dedicated workshops in each region to explore options and define 'representative enterprises' for modelling, (3) bio-economic modelling of the impacts the most promising 'best-bet' options have on landscape degradation and production, and (4) applied testing and extension of the 'best-bet 'options.

The bio-economic modelling component is being conducted jointly between DEEDI and CSIRO. It explores the production, resource condition and financial implications of northern beef enterprises adopting more promising strategies that have been revealed through the science review and landholder workshop phases. These strategies are being screened through a simulation modelling process that combines a pasture and animal production model (GRASP) with a dynamic beef herd economic model (ENTERPRISE) that is calibrated to mimic representative beef enterprises defined by the landholder workshops for each region.

Four herd and pasture management strategies are being explored in each region:

(a) Stocking rates - particularly variable versus fixed stocking rate regimes.

(b) Wet season pasture spelling - resting systems based on variable paddock rotations, spelling commencement and duration.

(c) Prescribed fire for woody vegetation control - fire regimes of varying frequency, starting tree basal area etc.

(d) Infrastructure - strategic expansion and location of stock waters, fencing etc.

An illustration of the modelling process is provided to compare stocking rates in the Fitzroy River basin region in the Fitzroy River Basin region, using a hypothetical 10,500 ha property located at Duaringa. The property comprises 15 paddocks of native and sown pastures carrying $\sim 1200$ breeding cows and turning off 590-600 kg bullocks to north Asian markets. Simulations of 25 years (1986 to 2010) were run using climatic records for Duaringa for three stocking rate strategies; viz - set stocking rates and two variable stocking rates that involve either constrained or unlimited variation in response to pasture availability.

\section{METHODS}

\subsection{Overall NGS Process}

The broad strategy of the NGS program is to: (1) formally review past research conducted by many agencies and institutions on many management issues across many locations in northern Australia. The objective is to identify central themes and underlying principles that might be applied to practical management in the major pastoral regions (McIvor et al. 2010). (2) Present strategies built around these themes at workshops of local landholders, research and extension specialists in nine defined regions representing major climate, vegetation and production zones of the northern grazing regions. Each regional workshop agrees on management strategies that are of interest for further exploration by simulation modelling and defines a synthetic beef enterprise that is representative of a broad cross-section of enterprises in the region. (3) Explore strategies or scenarios of interest through a process of bioeconomic modelling applied to locations and enterprise structures defined by the regional workshops. (4) Canvass results of the modelling effort for endorsement at a second series of regional workshops of similar composition to the original workshops. Refinements to the modelling scenarios will be undertaken using suggestions from the workshops. These suggestions in conjunction with the initial research review will provide insight into further research to fill existing knowledge gaps or follow through on technical questions raised by the modelling effort. (5) Conclusions from both the second regional workshops and modelling process will inform a series of on-property confirmation and demonstration trials that are based 
on the most promising herd and pasture management strategies for each region. The last step in NGS is occurring at the time or writing. The NGS multi-step process is summarised in Figure 1.

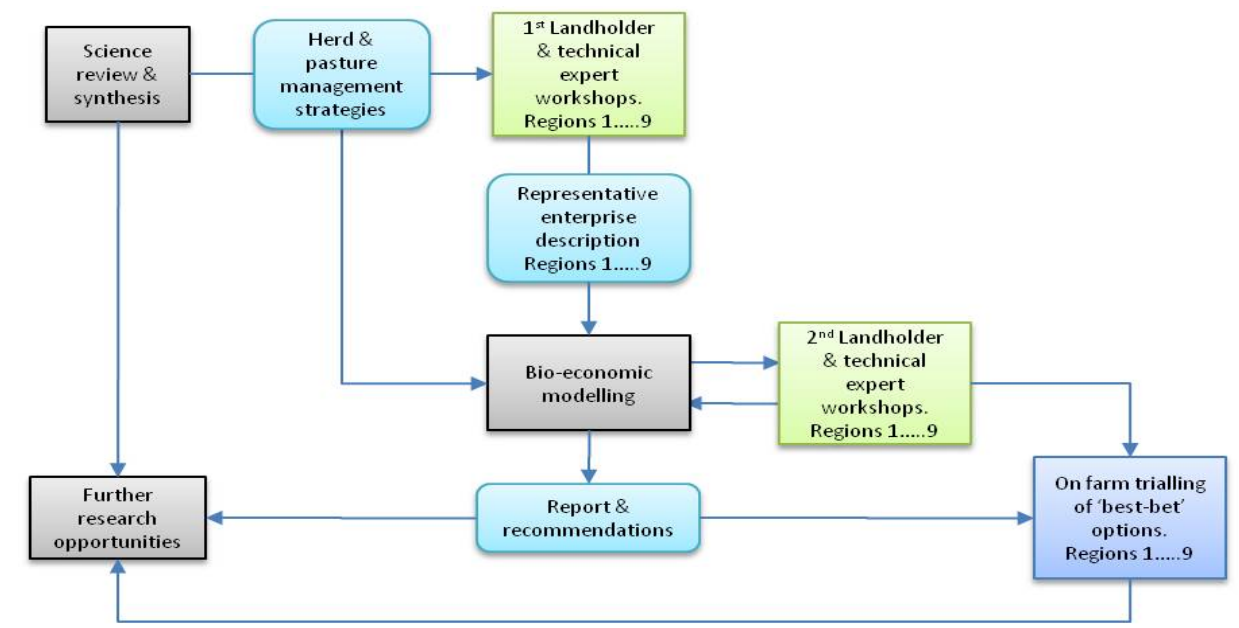

Figure 1. Schematic diagram of Northern Grazing Systems project process.

\subsection{Bio-Economic Modelling}

The modelling method and outcome is described for illustration in one of the nine project regions. Full details of all regions are contained in the NGS project report (Scanlan and McIvor 2010). A representative beef enterprise was defined by landholders and beef extension specialists at a workshop in Emerald in April 2009. The enterprise is characterised by a 10,500 ha property located near Duaringa $\left(23.71^{\circ} \mathrm{S}\right.$, $149.67^{\circ} \mathrm{E}, 94 \mathrm{~m} \mathrm{AMSL}$, av. annual rainfall 1885-2006 = $704 \mathrm{~mm}$, av. annual rainfall 1980-2006 = 613 $\mathrm{mm}$ ) comprising 15 paddocks of native and sown pastures carrying $\sim 1200$ breeding cows and turning off finished 590-600 kg bullocks to north Asian markets. Condition of the 15 paddocks varies from 'B good' to ' $\mathrm{C}$ - poor and degraded' as rated against a 4 category $\mathrm{ABCD}$ land condition rating system that is commonly employed by State land management agencies in northern Australia (Chilcott et al. 2003).

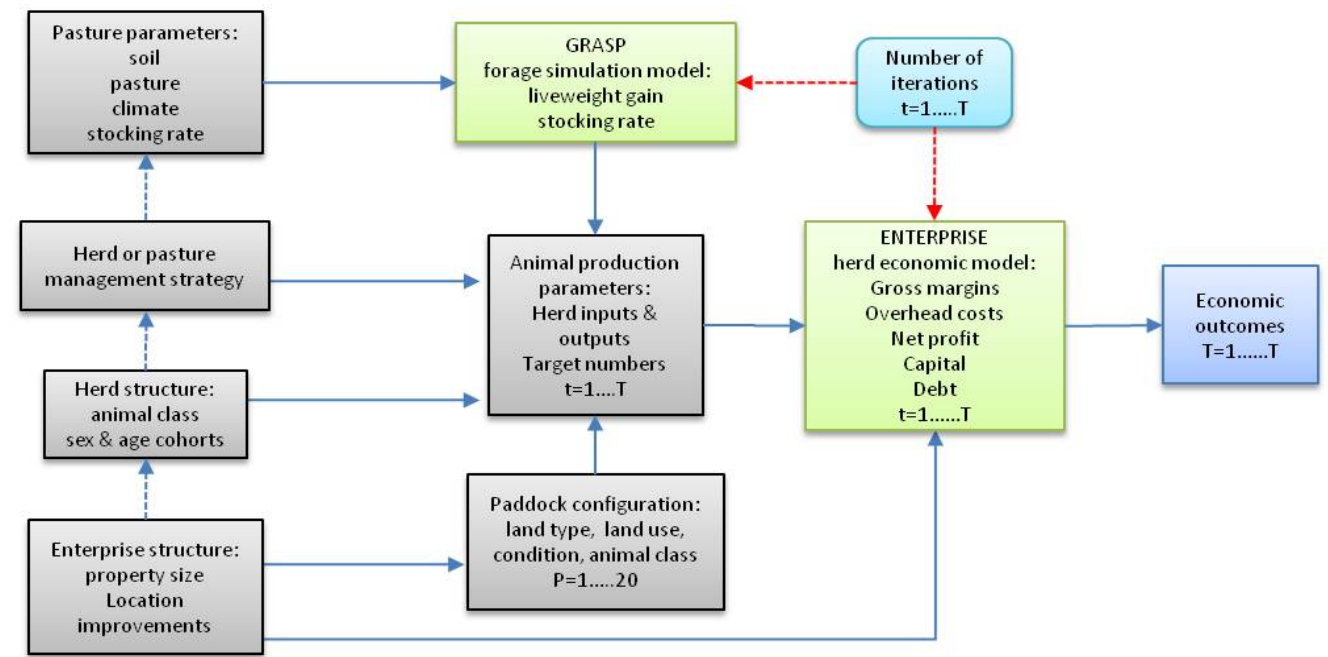

Figure 2. General structure of the GRASP-ENTERPRISE simulation modelling processes.

Pasture yield, annual carrying capacity and animal liveweight gain for the particular management practices being explored are estimated for each paddock using the GRASP pasture simulation model (McKeon et al. 1990). GRASP is a dynamic, deterministic, point-based model that simulates soil moisture, pasture growth and animal production from daily inputs of rainfall, temperature, humidity, pan evaporation and solar radiation. Parameter values and soil types of the 15 paddocks were input into GRASP. The annual liveweight gain of animals is simulated as a function of forage utilisation and growing season length (green days). The effect of land condition is assessed using a combination of percentage of perennial grasses in the pasture sward and basal area of the grasses. Projected liveweight gain and stocking rate for each paddock is derived from GRASP and input to a variant of the 
ENTERPRISE herd economic model (MacLeod and Ash 2001) that can allocate components of a herd to a maximum of 20 paddocks. Herd fertility and mortality rates which underpin the herd population dynamics are estimated within ENTERPRISE from the liveweight gain projections using regression equations based on herd records from Swans Lagoon Research Station (MacLeod et al. 2004). The model projects total animal numbers by sex and age class, animal turnoff rates for each year of a simulation trial and a range of profitability measures, including gross margins, net profit and ranges for these measures (Figure 2). Simulations of 25 years were run using climatic data for Duaringa from 1986 to 2010.

\subsection{Modelling example - fixed versus variable stocking rates}

Declining condition of rangeland pastures is generally typified by reductions in the proportion of palatable perennial tussock grasses, increases in annual grasses and forbs, and increases in the amount of bare ground (McIvor and Orr 1991). Overgrazing is a principal cause of such changes and adopting conservative stocking rates or ensuring flexibility in setting annual stocking rates is argued to be a critical consideration for sustainable pasture management (McKeon et al. 1990).

The example simulation compares a fixed stocking rate strategy with two strategies that allow some variation in annual stocking rate in response to changing seasonal conditions and associated forage availability. The 'safe' long term fixed stocking rate is set for each paddock at the assessed long term average safe utilisation rate $(\sim 20-25 \%)$ of standing pasture dry matter at the end of the growing season (e.g. Whish 2011). The two variable strategies are defined as seasonally responsive and constrained variation. The former strategy has a stocking rate in each paddock set each year according to a safe utilisation rate of standing dry matter (20-25\%) at the end of the growing season and remains unchanged for the following 12 months. The latter strategy allows a $10 \%$ increase or $20 \%$ decrease in stocking rate between individual years subject to an absolute limit of $20 \%$ above or $40 \%$ below the stocking rate that is set at the start of the simulation period. Comparisons were made of simulation outputs for each paddock over the 25-year simulation period.

\section{RESULTS}

The simulations involved large numbers of GRASP runs. The representative enterprise included seven land/vegetation types in 15 paddocks, nine of which were assumed to be in 'B - good condition' and the remaining six paddocks in 'C - poor condition'. The GRASP simulation results are presented for one of the 15 paddocks and its constituent land class - a cleared paddock comprising brigalow-blackbutt vegetation type (Whish 2011) in 'B - good condition' at the commencement of the simulation.

\subsection{Stocking rate, pasture condition, animal production}

\section{Stocking rate}

The fixed stocking rate is set in accordance with the safe utilisation rate estimated for the average rainfall of the simulation run. The flexible stocking rates fluctuate within the limits defined above.

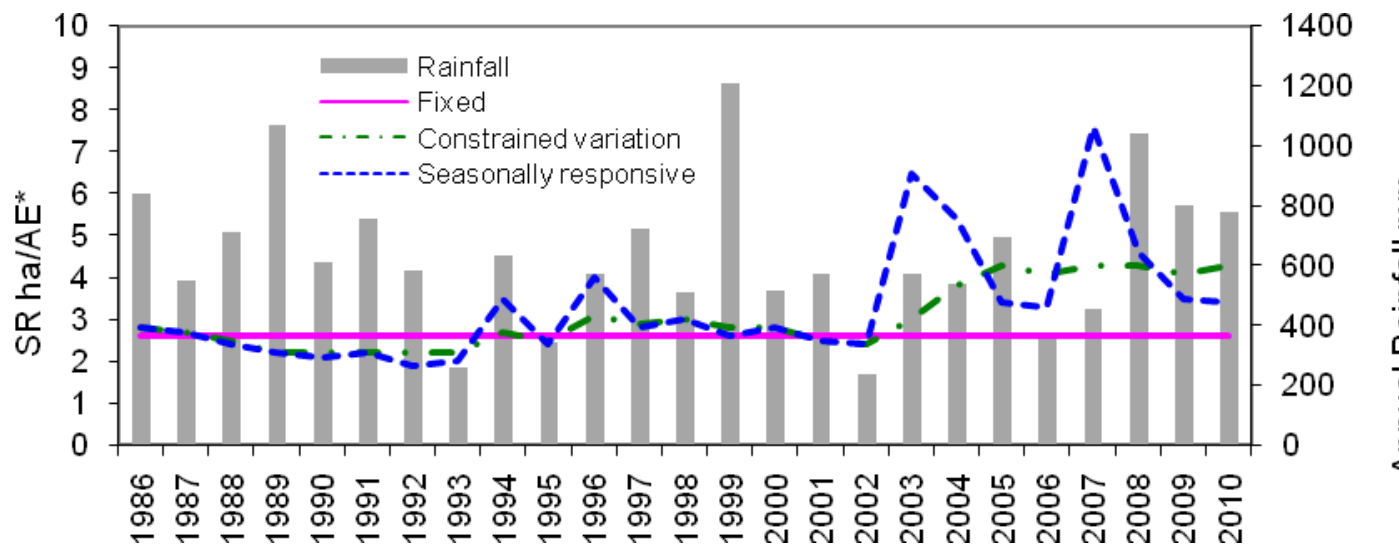

Figure 3. GRASP projections of annual carrying capacity for three stocking rate strategies on 'B- good condition' cleared brigalow-blackbutt pasture, Duaringa (1986-2010). * 1 Adult Equivalent (AE) $=455 \mathrm{~kg}$ non-pregnant, non-lactating cow. 
The two variable stocking rate strategies decreased the carrying capacity of the paddock by the end of the simulation period (Figure 3). This is largely because of pasture damage caused by holding excessive numbers on pastures when good rainfall years are followed by poor rainfall years (Scanlan and McIvor 2010). The fixed stocking rate by definition did not change over the simulation period.

\section{Pasture condition - \% perennials}

The impact of stocking rates on pasture condition as measured by $\%$ composition of perennial grasses in the sward is illustrated in Figure 4.

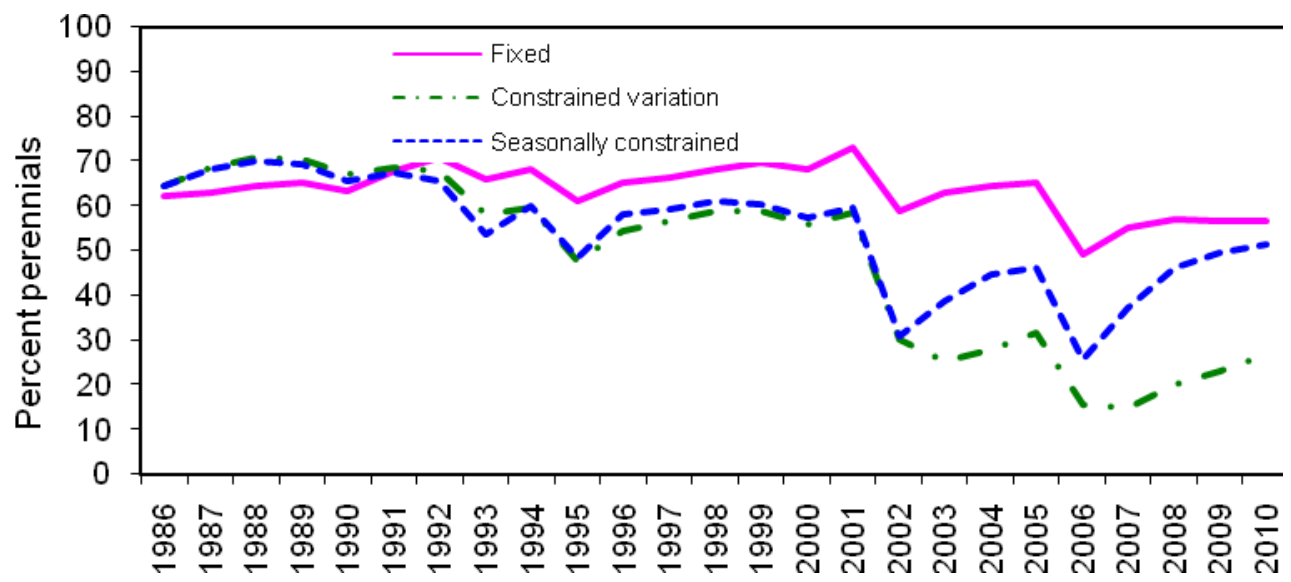

Figure 4. GRASP projections on \% perennials for three stocking rate strategies on 'B- good condition' cleared brigalow-blackbutt pasture, Duaringa (1986-2010).

The two seasonally adjusted stocking rate strategies can potentially reduce cattle numbers when forage availability is low, and reduce the risk of overgrazing. However, all three strategies overshot animal numbers early in the simulation period with subsequent decline in percentage of perennials. The more restrictive constrained strategy, unlike the seasonally constrained strategy, prevented sufficient reduction in cattle numbers to stop serious pasture damage which lead to a longer recovery at the end of the simulation.

\section{Animal performance - liveweight gain per hectare}

Liveweight gain per hectare provides a measure of animal productivity for a grazing enterprise (MacLeod et al. 2004), and is illustrated in Figure 5.

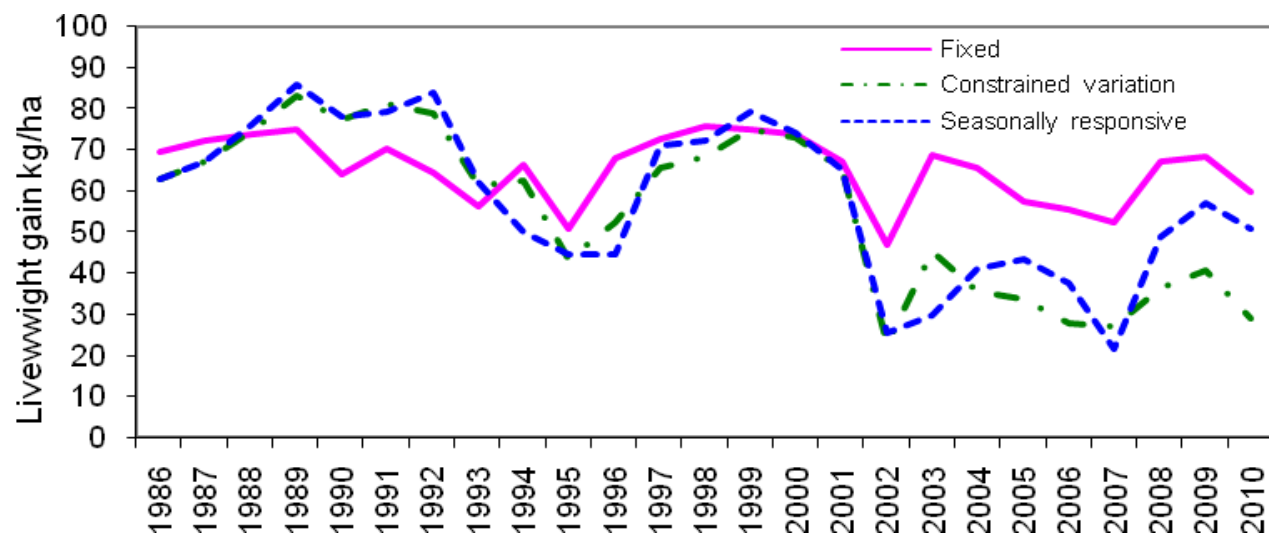

Figure 5. GRASP projections on liveweight gain per hectare for three stocking rate strategies on 'B- good condition' cleared brigalow-blackbutt pasture, Duaringa (1986-2010).

The stocking rate used as the 'safe' fixed stocking rate (Figure 3) maintained pasture condition better than the variable strategies (Figure 4), and produced higher average liveweight gains per hectare at the end of the period (Figure 5). Both variable stocking strategies tended to yield higher gains in first half of the 
simulation when pasture conditions improved (Figures 4 and 5). The seasonally responsive strategy outperformed the constrained variation strategy because animal numbers were adjusted more rapidly in the face of changing conditions.

\subsection{Profit}

ENTERPRISE produces a wide array of profit metrics for a given simulation (MacLeod and Ash 2001). Average, minimum and maximum annual profit (total revenue minus total costs) and the number of years the annual estimate was negative for the three stocking rate strategies is presented in Table 1.

Table 1. Estimated annual total profit for three stocking rate management strategies on the representative Duaringa enterprise (mean values for simulation period 1986-2010).

\begin{tabular}{cccc}
\hline & Fixed Stocking Rate & Constrained variation & Seasonally responsive \\
\hline Average & $\$ 204,401$ & $\$ 77,370$ & $\$ 135,536$ \\
Minimum & $-\$ 64,425$ & $-\$ 183,421$ & $-\$ 313,983$ \\
Maximum & $\$ 490,670$ & $\$ 346,240$ & $\$ 743,838$ \\
Negative Yrs & 3 & 8 & 11 \\
\hline
\end{tabular}

The fixed safe stocking rate strategy produced the highest annual average profit, followed in decreasing order by seasonally responsive and constrained variation strategies Table 1). Fixed stocking also had the highest minimum profit and the least number of years when profit was negative. As stocking rate flexibility increased, the number of years when annual profit was negative tended to increase as well, as did the range in profit over the 25 year simulation period.

\section{DISCUSSION}

The results presented are to illustrate the utility of the NGS bio-economic modelling approach. In the example of the Duaringa representative enterprise, the projected response in terms of carrying capacity, resource condition, animal production and profitability for the various stocking rate management options revealed the 'extremes' of the flexibility strategies were generally the most profitable under the climatic conditions between 1986 and 2010. The 'safe' fixed stocking rate option was the most profitable $(\$ 204,401)$, on average generating approximately $\$ 70,000$ more per annum than the unconstrained seasonally responsive strategy. The constrained variation strategy which nominally allows a little more flexibility than the 'safe' fixed stocking rate performed quite poorly $(\$ 77,370)$ generating around half the annual profit of the seasonally responsive strategies. Annual adjustment of animal numbers, within the limits explored here, from a conservative stocking rate that maintains pasture in the starting condition (both 'B' good and ' $\mathrm{C}$ ' poor condition) over the 25 year simulation did not improve the economic outcomes for the Duaringa enterprise. Nevertheless, the results are highly context-dependent and reflect a combination of the particular stocking rate strategies, the land/vegetation types, land condition and climatic conditions in the place and time of the simulation trial. These results were canvassed at the second landholder workshop which was held in Emerald in April 2010 and generally endorsed by the participants. Insights from the modelling output for all the herd and land management strategies that were explored as part of the NGS process (i.e. stocking rates, seasonal resting, prescribed fire etc) have been incorporated into local extension materials for use in the Fitzroy region.

Different combinations of these factors and particularly the climatic sequence will have a major bearing on the outcomes of the strategies under review. This was evident from other NGS regional studies (e.g. Western Queensland, Burdekin) which ranked the performance of the same three stocking rate strategies over the same 25 year simulation period in the reverse order to that presented for Duaringa. This outcome is largely attributed to the climatic conditions for these regions being almost symmetrically opposite leading to different patterns of pasture response and animal performance over the simulations as well as different scope for exceeding or staying within critical pasture degradation thresholds during a particular simulation. An ongoing effort is being put in to testing the various herd and land management strategies under different climatic sequences in each of the project regions including under projected climate change scenarios, to seek principles and the scope for enhanced forecasting to inform management. 


\section{CONCLUSION}

The NGS process which includes the bio-economic modelling of 'representative' grazing enterprises constructed around a process of science review and landholder pastoralist consensus has offered considerable scope for defining sustainable grazing land management practices with both economic potential and high levels of producer ownership. The results presented offer only a limited insight into the full potential of the underpinning pasture production and herd dynamic models, GRASP and ENTERPRISE, to explore grazing land management options in some detail. With declining funds for conducting grazing land management trials, the simulation modelling approach offers a useful alternative for screening large numbers of management options and strategies for future application in research or practice. The final phase of on-farm demonstration sites has now commenced in all the NGS regions including the Fitzroy region (Bray et al. 2011). This will complete the overall process of taking research knowledge from field trials and laboratories through to local practice. The intermediate contribution of applied bio-economic modelling to this outcome is significant.

\section{ACKNOWLEDGEMENTS}

The NGS project was funded under Meat and Livestock Australia project B.NBP.0578 'Enhancing adoption of improved grazing and fire management practices in Northern Australia: Bio-economic analysis and regional assessment of management options'. The assistance of DEEDI beef extension officers and landholder panellists from the Fitzroy region of Central Queensland is appreciated.

\section{REFERENCES}

Bray, S., D. Walsh, D. Phelps, and C. Stokes (2011). Climate Clever Beef - 1. Improving beef business resilience. Contributed paper to Northern Beef Research Update Conference, Darwin, Meat and Livestock Australia, Sydney, August 2-5.

Chilcott, C. R., B.S. McCallum, M.F. Quirk, and C.J. Paton (2003) Grazing Land Management Education Package Workshop Notes - Burdekin. Meat and Livestock Australia Limited, Sydney.

MacLeod, N.D., and A.A. Ash (2001). Development of a spreadsheet herd dynamics model to assess the economic value of forecasts in extensive grazing enterprises. Oceans to Farms Project Report No.6, CSIRO Sustainable Ecosystems, Brisbane and Townsville.

MacLeod, N.D., A.A. Ash, and J.G. McIvor (2004). An economic assessment of the impact of grazing land condition on livestock performance in tropical woodlands. Rangeland Journal. 26(1), 49-71.

McIvor, J.G., and D.M. Orr (1991). Sustaining productive pastures in the tropics. 3. Managing native grasslands. Tropical Grasslands 25, 91-97.

McIvor, J.G., S.G. Bray, A.C. Grice, and L.P. Hunt (2010). Grazing management guidelines for northern Australia: Scientific rationale and justification. In. (J.G. McIvor Ed.) Final report MLA project NBP.0579 - Enhancing adoption of improved grazing and fire management practices in northern Australia: Synthesis of research and identification of best-bet management guidelines. Brisbane.

McKeon, G.M., K.A. Day, S.M. Howden, J.J. Mott, D.M. Orr, W.J. Scattini, and E.J. Weston (1990). Northern Australian savannas: Management for pastoral production. Journal of Biogeography 17, 355372.

Scanlan, J.C., and J.G. McIvor (2010). Enhancing Adoption of Best Practice Grazing Management in Northern Australia: Phase One - Integration and Scenario Testing. Final Technical Report: Caring for Our Country Project OG084273, Meat and Livestock Australia, Sydney.

Tothill, J.C., and C. Gillies (1993). The pasture lands of northern Australia. Tropical Grasslands Society of Australia, Occasional Publication No.5, Brisbane.

Whish, G.L. (2011). Land types of Queensland. Version 2.0. Prepared by the Grazing Land Management Workshop Team, PR07-3212, Department of Employment, Economic Development and Innovation, Brisbane. 